\title{
Energy system modelling - interactions and synergies in a highly renewable Pan-European power system
}

\author{
Stefan Weitemeyer ${ }^{\mathrm{a}}$, David Kleinhans, Thomas Vogt and Carsten Agert \\ NEXT ENERGY - EWE Research Centre for Energy Technology at the University of Oldenburg, \\ Carl-von-Ossietzky-Straße 15, 26129 Oldenburg, Germany
}

\begin{abstract}
It is very likely that the European power supply system will be transformed in the next decades to a low carbon system based almost entirely on Renewable Energy Sources (RES). However, due to the natural fluctuations of the most powerful RES (wind and solar energy), it is also very likely that a significant amount of balancing and controllable backup power capacities will be required to ensure a stable grid operation. This implies high additional investments and operating costs. Therefore this work provides an overview of potential options and possibly more cost-effective alternatives to the installation of costly storage capacities, namely grid expansion, demand side management, an optimised mix between different RES as well as the use of overcapacities. Furthermore, the paper provides an approximation of the maximum RES penetration of the German electricity system in the absence of significant storage capacities. Our calculations show that from a numerical perspective on average approximately half of the load can be met by RES if flexible conventional power stations would provide the remaining electricity demand. However, in a $100 \%$ RES scenario a significant amount of storage capacities as well as limited overcapacities are required to ensure a reliable electricity supply.
\end{abstract}

\section{Introduction}

The continuous availability of energy in general and electricity in particular is an essential requirement for society in Europe today. Ongoing concerns about climate change as well as the aim of many countries to become independent from energy imports raise the question how the future power supply system in Europe will look like. Renewable Energies Sources (RES) are one source of electricity which will most likely gain importance in upcoming years.

There are many studies on the future European power system in the next decades, with the share of RES ranging from about $40 \%$ (by 2040) [1] to up to 100\% (by 2050) [2-5]. In particular electricity production from wind and solar resources are considered in these studies as these have the highest potential in Europe [6]. However, the large-scale integration of RES gives rise to different challenges which still need to be met, e.g. technical issues like voltage stability or black-start capability and economic issues like investments in infrastructure and new market models to name but a few. On a

\footnotetext{
${ }^{\text {a }}$ Corresponding author: stefan.weitemeyer@next-energy . de
}

This is an Open Access article distributed under the terms of the Creative Commons Attribution License 4.0, which permits unrestricted use, distribution, and reproduction in any medium, provided the original work is properly cited. 
larger scale, one could even consider this process a major transformation of the power supply system as in scenarios with a high share of RES the production of electricity is not driven anymore primarily by the consumer but it is the weather which decides when and where electricity can be fed in. As production and consumption in power grids always need to be balanced, fluctuations in the availability of the resources wind and solar can lead to a need for a significant amount of balancing and controlling backup power capacities to ensure grid stability at high penetration levels of production from RES [7,8]. Usually it is assumed that the backup power is provided either by conventional power plants or by storage systems $[8,9]$, where the installation of storages is the only option which is able to achieve a significant degree of sustainability. However, this would imply high investments and operating costs; capital cost in the order of $10 \$ / \mathrm{kWh}$ for pumped-hydro storage would e.g. lead to total costs in the order of a trillion dollar for some of the investigated scenarios [10]. Hence alternatives to storage should also be considered. In this paper, an overview of four sustainable alternatives to the installation of storage capacities is given, namely grid expansion, demand side management, an optimised mix between different RES as well as the use of overcapacities.

\section{Energy storage and its alternatives}

One of the main challenges of the integration of RES into a power supply system is the fact that the production from the sources with the highest potential (solar and wind energy) is fluctuating as they depend on the weather. Since electricity is a key requirement for our society, the imbalances between the production from variable RES on one hand and the load on the other hand continuously need to be balanced. One option would be simply to use back-up power plants in the form of e.g. flexible gas power plants to provide the electricity when there is a deficit in the grid. However, studies have shown that in a system with a RES share of $80 \%$ this would very likely require backup capacities equalling to about $70 \%$ of today's power plant capacities [7, 11]. Another option would be the installation of storage capacities, where energy is stored at times of excess generation from RES and it is fed into the system again in times of deficit. In a hypothetical system based completely on solar and wind resources, the required storage capacities for Europe is estimated to be in the order of $400 \mathrm{TWh}$ though $[8,12]$. Besides the costs of large storage capacities, the question arises if we would even be able to build up the required storage capacities in Europe as chemical storage devices are currently the only technology suitable for such high amounts of energy $[10,13]$. Hence, alternative options should be considered.

\subsection{Grid expansion}

The first alternative option to be discussed in this work is the expansion of the European transmission grid. As one can easily observe on weather maps, changes in the weather occur on a synoptic scale of hundreds to thousand kilometres. For the power production from RES this means that a lack of wind resources in one region might not be balanced out by a surplus from a neighbouring region, but it is likely that the conditions are much different in other parts of Europe. Hence, an expansion of the European transmission grid would allow distributing production and loading over larger distances (cf. Fig. 1).

Already today there exists the large-scale synchronous grid of Continental Europe, which in principle allows electricity to flow e.g. from Poland to Portugal and from Denmark to Greece, furthermore connections to the Nordic countries as well as to the British Islands exist. The grid was, however, historically not designed for a large-scale transfer of electricity as every country has its own power plants, thus the sum of the net transfer capacities between countries in Europe (ENTSO-E area) is about $73 \mathrm{GW}$ nowadays compared to a maximum load of around $540 \mathrm{GW}$ in the same area $[14,15]$. It was recently estimated that in a hypothetical scenario with a complete coverage of the demand by solar and wind resources, the need for balancing energy would be reduced from $21 \%$ to $15.1 \%$ of the annual consumption if the grid is assumed to have no transmission capacity constraints [16]. Thus, by 


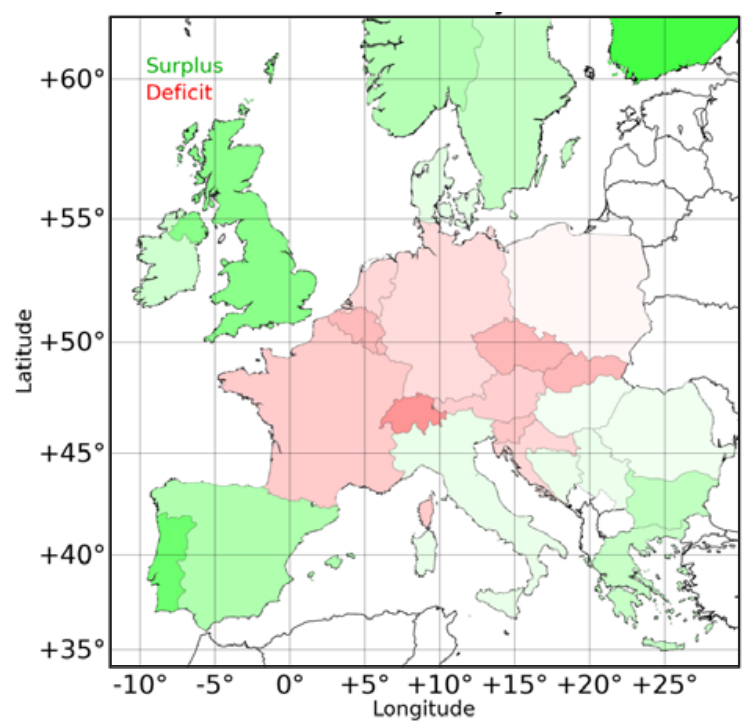

Figure 1. Example for the distribution of surplus and deficit energy in different countries in Europe in an exemplary hour (midday) for a simulated scenario with a $100 \%$ penetration of solar and wind energy.

expanding the transmission grid capacities, production and demand could be smoothed out over large areas which will very likely reduce the need for storage and back-up power capacities [17]. However, even unlimited transmission capacities will not be able to balance out production deficits when there is hardly any electricity production from RES anywhere in Europe, e.g. in a calm night, thus even a massive expansion cannot complete dissolve the need for storage or back-up capacities.

\subsection{Demand-side management}

The second aspect which will play an important role for the integration of RES into the power system is the use of demand-side management (DSM) methods. ${ }^{1}$ As mentioned before, the feed-in of electricity into the grid in a highly-renewable energy supply system is strongly influenced by the weather. Thus it is beneficial to consume electricity in times with high generation of electricity from RES. Demandside management can be regarded as a generic term for all methods where the demand is actively manipulated. In general, two classes of DSM can be distinguished. The first one is curtailment, meaning that the energy demand is decreased temporally by switching off devices. This generally has a high impact on the consumer, hence it is mainly used by large systemic consumers only (e.g. aluminium industry). The more applicable class of DSM is load shifting, where the energy demand is conserved. In this respect, load shifting can be regarded as being analogue to an energy storage device. In order to be able to integrate DSM in energy system models, there is a need to characterise load shifting in a quantitative way. By considering the scheduled loads as a reference the storage-equivalent potential of these devices is estimated to be in the order of $100 \mathrm{GWh} / 30 \mathrm{GW}$ for Germany, whereupon heating devices account for the largest contribution [18]. This is orders of magnitudes lower than the demand for long-term storage mentioned above. However, DSM certainly has a potential to replace short-term storage in future power systems [19].

\footnotetext{
${ }^{1}$ In other publications also referred to as load management or demand response.
} 


\subsection{Optimised mix}

A third option to reduce the demand for storage or back-up capacities is to optimise the mix between different RES in a prospective power supply system. Besides the well-known fluctuations of wind and solar power on an hourly or daily scale, the possible production from these resources in Europe also varies on a seasonal scale, with the production from wind resources being much higher in winter compared to summer. The contrary is the case for solar power. As the load in Europe is currently only slightly higher in winter than in summer [15], combining wind and solar resources will reduce the need for storage compared to scenarios where only one of the two resources is used. To be more precise, it was estimated that for a scenario based entirely on wind and solar resources with a share of about 55\% wind and about $45 \%$ solar energy, the required storage energy would be equivalent to about 1.5 average monthly consumption compared to almost twice as much for a wind-only or solar-only scenario [7]. It is worth mentioning, though, that the results for the optimised mix might be influenced by future changes in the demand characteristics. A higher load during the day (e.g. by charging electrical vehicles at work) or during the summer (e.g. by the large-scale usage of air-conditioning throughout Europe) will likely lead to a better usability of solar resources. This example also illustrates the importance of studying the overall system with all relevant aspect to identify synergies and not to strictly focus on individual aspects only.

\section{4 (Over-)capacities}

The fourth and last aspect to be discussed in this work regarding the large-scale integration of RES is the use of overcapacities. ${ }^{2}$ Already with the power plants installed today rather substantial overcapacities are realised, since balancing requires that the installed capacities are scaled upon worst-case situations of the consumption patterns. Also a prospective European power supply systems based on RES needs to be adjusted to peaks in the demands. One option would be to cover seasonal peaks in the demand at low production from RES by storage or back-up capacities only, which would imply a need for the installation of seasonal storages $[12,17]$. By instead installing overcapacities for the conversion from RES, the need of large seasonal storage and the peak demand in balancing capacities (determining the required power of the storage or back-up capacities) can be reduced significantly [12]. As a further benefit, the excess generation in times of overproduction could be used to e.g. produce hydrogen to be used for heating or transport [20]. However, as additional capacities would also mean additional costs as well as possible curtailment in parts of the year, a balance between the installation of overcapacities and the installation of back-up or storage capacities has to be found.

\section{Timing for storage installation}

Since the share of electricity production from fluctuating RES in most countries and regions today is rather small, curtailment and storage is not a major issue yet. It has however been estimated that even in systems with only about $40 \%$ of the electricity being produced from wind energy the production from RES occasionally can be higher than the load, requiring a curtailment of the electricity production due to the absence of storage capacities [21]. Since the impact of the share of electricity produced from RES on the curtailment and its correlation with the availability of energy storages is of high technical and economical relevance for the further installation of conversion capacities, this issue was investigated systematically with a conceptual model.

\footnotetext{
${ }^{2}$ In this work, the term is used for excess generation capacities, meaning part of the theoretically producible energy in some hours is not used but curtailed.
} 
For this purpose model simulations were conducted for Germany. For the calculations, long-term solar $\mathrm{S}(\mathrm{t})$ and wind energy $\mathrm{W}(\mathrm{t})$ power output data series with hourly resolution were used to estimate the production from RES for Germany as a function of their respective shares in the energy production. The data was aggregated for the whole country, which was considered as a copper plate, i.e. grid effects were not taken into account. The production from the RES was put into relation to the respective demand $\mathrm{L}(\mathrm{t})$. All time series are normalised to their long-term-average (eight years of data in this case). The hourly energy surplus $\Delta(\mathrm{t})$ is then defined as (c.f. [7]):

$$
\Delta(\mathrm{t})=\gamma(\alpha \mathrm{W}(\mathrm{t})+(1-\alpha) \mathrm{S}(\mathrm{t}))-\mathrm{L}(\mathrm{t})
$$

with $\gamma$ being the renewable energy penetration factor $^{3}$ and $\alpha$ being the share of wind power generation. For the results shown below, the wind share was fixed to $\alpha=0.60$.

At times with negative values of $\Delta(\mathrm{t})$ the load could not be covered from the production from RES. These residual loads instead need to be covered from energy storages or fossil production capacities. In our modelling approach energy deficits are covered from a hypothetical storage device with round-trip efficiency $\eta$, which is not restricted in size; surplus energy is used to charge this storage. A storage time series $\mathrm{H}(\mathrm{t})$ describing the energy available to the grid is calculated as

$$
H(t)=H(t-1)+ \begin{cases}\eta \Delta(\mathrm{t}) ; & \text { if } \Delta(\mathrm{t}) \geq 0 \\ \Delta(\mathrm{t}) ; & \text { if } \Delta(\mathrm{t})<0\end{cases}
$$

$\mathrm{H}(\mathrm{t}=0)$ without loss of generality was set to 0 . The value of $\mathrm{H}$ at the end of the simulation determines the long term coverage of the production from RES: If $\mathrm{H}\left(\mathrm{t}_{\mathrm{end}}\right) \geq 0$, production from RES in combination with the hypothetical storage device can cover the demand in the long run implying a share of production from RES of $100 \%$. However if $\mathrm{H}\left(\mathrm{t}_{\mathrm{end}}\right)<0$ there is a general energy deficit in the system. We here assumed that this deficit would need to be covered by non-RES sources decreasing the overall share of load covered from RES. Figure 2 shows the resulting shares of production from RES as a function of $\gamma$ for different storages with round-trip efficiencies (a) $\eta=100 \%$ (perfect storage), (b) $\eta=80 \%$ (e.g. pumped hydro storage), (c) $\eta=40 \%$ (e.g. hydrogen storage) and (d) $\eta=0 \%$ ("no storage").

It is evident that the slope of the curves does not vary significantly for $\gamma \leq 0.5$. This means that from a numerical and balance-sheet perspective RES capacities at $\alpha=0.60$ can be integrated into the system up to a share of about $50 \%$ production from RES without the need for the integration of significant storage capacities - provided that the remaining conventional power stations can be operated highly flexibly. It is furthermore observed that after this transition point, the curve for the "no storage" scenario (d) flattens. This means that even the installation of significant over-capacities $(\gamma \gg 1)$ would not imply a $100 \%$ coverage of the demand by RES. Hence, it can be assumed that the installation of storage capacities will likely become important with a further integration of RES in Germany, in particular after the transition point of about $50 \%$ coverage of the production. The round-trip efficiency $\eta$ has an effect on the slope of the curves after this transition point. As a round-trip efficiency of $\eta<1$ implies that part of the energy is lost during storage (e.g. due to conversion losses) and thus cannot be used to cover the load, $\gamma>1$ is required to reach a coverage of $100 \%$ of the energy consumption for the cases (b) and (c). A perfect, loss-free and unlimited storage (a) would allow for perfect integration of all RES into the system, but even with a non-perfect storage (e.g. pumped hydro or hydrogen storage), a scenario of $100 \%$ RES appears feasible, though at limited overcapacities. Although not considered here, also controllable RES like biomass or hydro could be used to cover parts of the energy deficits. Therefore,

\footnotetext{
${ }^{3}$ A renewable energy penetration factor of $\gamma=1.0$ would reflect a scenario where the annual production from RES is equal to the annual demand.
} 


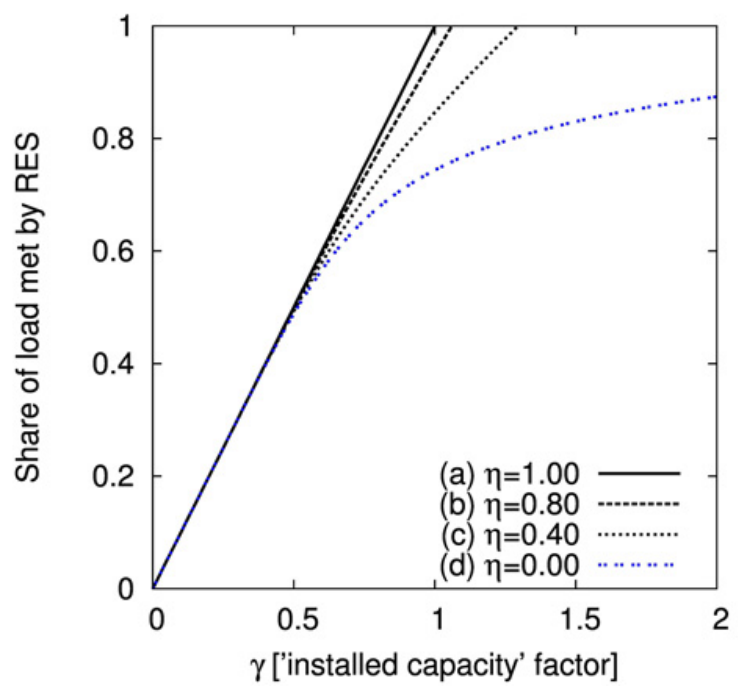

Figure 2. Share of load which can be met by RES as a function of the installed capacity $\gamma$ for storage devices with unlimited size and different round-trip efficiencies $\eta$.

covering $90-95 \%$ of the consumption by wind and solar in fact might be sufficient for an electricity sector based entirely on renewable resources.

\section{Conclusions}

The transformation of the European power supply system to a system with a high share of fluctuating Renewable Energy Sources is a challenging but achievable task. As this transformation will likely lead to significant changes in our electricity system, studying future scenarios does involve uncertainties. However, aspects like the expansion of the European transmission grid or the construction of new power plants are long-term decisions; hence there is an urgent need for long-term strategic and conceptual investigations.

The installation of either massive storage or excess generation capacities would theoretically be sufficient to achieve a power supply system in Europe which is based almost entirely on RES. However, choosing only one of these options might not be the most cost-effective way of achieving this goal, as shown e.g. in Fig. 2. Hence a combination of storage capacities and limited overcapacities seems to be most beneficial from our investigations. Furthermore, the expansion of the transmission grid, the use of demand-side management and an optimised mix between different RES will allow further reducing the demand for storage or generation capacities. As a cost-effective and stable supply of electricity is a necessity for society, storage and its alternatives should be considered when investigating scenarios of prospective power systems, e.g. by performing model simulations. During the further process, questions on the technical, economic, ecological and social dimensions also need to be addressed.

A general challenge in the investigation of prospective power supply scenarios is the availability of reliable data. The availability of reference data e.g. for meteorological conditions and loads would ease the comparison of different scenario analyses, which is an essential requirement to achieve the common goal of realising a cost-effective and stable supply of electricity based on Renewable Energy Sources. 
$3^{\text {rd }}$ European Energy Conference

\section{References}

[1] ExxonMobil, The Outlook for Energy: A View to 2040, http://corporate.exxonmobil. com/en/energy/energy-outlook (2012)

[2] European Energy Research Council, RE-thinking 2050, http://www.rethinking2050.eu (2010)

[3] PricewaterhouseCoopers, $100 \%$ renewable electricity - A roadmap to 2050 for Europe and North Africa, http://www.pwc.co.uk/assets/pdf/100-percent-renewable-electricity. pdf (2010)

[4] M. Faulstich et al., Pathways towards a $100 \%$ renewable electricity system, http: //www. umweltrat.de (2011)

[5] D. Connolly, H. Lund, B.V. Mathiesen, M. Leahy, Applied Energy 87, 1059-1082 (2010)

[6] M.Z. Jacobson, M.A. Delucchi, Energy Policy 39, 1154-1169 (2011)

[7] European Climate Foundation, Roadmap 2050 - A practical guide to a prosperous, low carbon Europe, http: //www.roadmap2050 .eu (2010)

[8] D. Heide, L. von Bremen, M. Greiner, C. Hoffmann, M. Speckmann, S. Bofinger, Renewable Energy 35, 2483-2489 (2010)

[9] C. Budischak, D. Sewell, H. Thomson, L. Mach, D.E. Veron, W. Kempton, Journal of Power Sources 225, 60-74 (2013)

[10] S.M. Schoenung, W.V. Hassenzahl, Long- vs. Short-Term Energy Storage Technologies Analysis - A Life-Cycle Cost Study, Sandia Report SAND2003-2783 (2003)

[11] European Commission, EU energy and transport in figures, http://ec.europa.eu (2010)

[12] D. Heide, M. Greiner, L. von Bremen, C. Hoffmann, Renewable Energy 36, 2515-2523 (2011)

[13] M. Gimeno-Gutierrez, Roberto Lacal-Arantegui, Assessment of the European potential for pumped hydropower energy storage, http://ec.europa.eu/dgs/jrc/ (2013)

[14] ENTSO-E, Indicative values for net transfer capacities (NTC) in continental Europe, https://www .entsoe.eu/publications/market-reports/ntc-values/ntc-matrix/ (2011)

[15] ENTSO-E, Statistical Yearbook 2011, https://www.entsoe.eu/publications/ statistics/ (2012)

[16] R.A. Rodriguez, S. Becker, G.A. Andresen, D. Heide, M. Greiner, Renewable Energy 63, 467-476 (2014)

[17] F. Steinke, P. Wolfrum, C. Hoffmann, Renewable Energy 50, 826-832 (2013)

[18] D. Kleinhans, Potential of Demand Side Management in Continental Europe, European Energy Conference, Poster, Budapest (2013)

[19] M.G. Rasmussen, G.B. Andresen, M. Greiner, Energy Policy 51, 642-651 (2012)

[20] M.A. Delucchi, M.Z. Jacobsen, Energy Policy 39, 1170-1190 (2011)

[21] E.K. Hart, E.D. Stoutenburg, M.Z. Jacobson, Proceedings of the IEEE 100(2), 322-334 (2012) 